\title{
Impacts of mechanical stiffness of bacteriophages-loaded hydrogels on their antibacterial activity
}

\author{
Grégory Francius $^{1 \#}$, Manon Cervulle ${ }^{1}$, Eloïse Clément ${ }^{1}$, Xavier Bellanger ${ }^{1}$, \\ Saeid Ekrami ${ }^{1}$, Christophe Gantzer ${ }^{1}$, Jérôme F.L. Duval ${ }^{2}$
}

${ }^{1}$ Université de Lorraine, CNRS, LCPME, F-54000 Nancy, France.

${ }^{2}$ Université de Lorraine, CNRS, LIEC, F-54000 Nancy, France.

\# Corresponding author:

gregory.francius@univ-lorraine.fr 


\begin{abstract}
The elaboration of novel and efficient hydrogel-based materials with antimicrobial properties requires a refined control of their defining physicochemical features, which includes mechanical stiffness, so as to properly mediate their antibacterial activity. In this work, we design hydrogels consisting of polyelectrolyte multilayer films for the loading of $\mathrm{T} 4$ and $\varphi \mathrm{X} 174$ bacteria-killing viruses, also called bacteriophages. We investigate the anti-adhesion and bactericidal performances of this biomaterial against Escherichia coli, with a specific focus on the effects of chemical cross-linking of the hydrogel matrix which, in turn, mediates the hydrogel stiffness. Depending on the latter and on phage replication features, it is found that the hydrogels loaded with the bacteria-killing viruses make it possible both contactkilling (targeted bacteria are those adhered at the hydrogel surface) and release killing (planktonic bacteria are the targets) with $c a .20 \%$ to $80 \%$ efficiency after only 4 hours incubation at $25^{\circ} \mathrm{C}$, as compared to cases where hydrogels are free of viruses. We further demonstrate the lack of dependence of virus diffusion within the hydrogel and of the maximal viral storage capacity on the hydrogel mechanical properties. In addition to the evidenced bacteriolytic activity of the phages loaded in the hydrogels, the antimicrobial property of the phages-loaded materials is shown to be partly controlled by the chemistry of the hydrogel skeleton and, more specifically, by the mobility of the peripheral free polycationic components, known for their ability to weaken and permeabilize membranes of bacteria, the latter then becoming 'easier' targets for the viruses.
\end{abstract}

\title{
Keywords:
}

Polyelectrolyte multilayer films, phages, antibacterial activity, infectivity, Atomic Force Microscopy. 


\section{Introduction}

Over the past decades, the amount of therapeutic failures caused by pathogenic bacteria having developed or acquired tolerance and resistance to antibiotics has dramatically increased. Antibiotic resistant bacteria may appear from spontaneous gene mutations and then outcompete sensitive bacteria upon therapeutic administration of antibiotics. ${ }^{1,2}$ Resistant bacteria can also disseminate their resistance genes to unrelated bacteria thanks to horizontal gene transfer mechanisms. ${ }^{3}$ Antibiotic resistance has been evidenced for a large variety of pathogens like Staphylococcus aureus, some of them having the capabilities to withstand even the newest antimicrobial agents. ${ }^{4-6}$ This serious public health issue leads the World Health Organization and governments to encourage the development of novel strategies to fight against antibiotic resistant pathogenic bacteria. Consequently, the current trend in fundamental and applied research is the development of new devices and methods able to offer a sound and efficient alternative to the traditional antibiotic treatments. Additional motivation for this new line of research is that oral uptake of drugs is not applicable or suitable for all antibiotic molecules, whereas e.g. transdermal plasters or patches allow the delivery of a wide class of antimicrobial agents. Conventional transdermal patches further make it possible a gradual and controlled release of the drugs over an extended period of time, a property that is generally required for antibiotic therapies to be successful. ${ }^{7,8}$

Transdermal plasters or patches are drug delivery systems defined as self-contained, discrete dosage form which can be applied directly onto the skin and can deliver the drug either topically or into the systemic circulation at a controlled rate. Currently, transdermal drug delivery systems are viewed as one of the most promising strategies for efficient delivery of drugs and of other antimicrobial agents into the systemic circulation. The important role played by topical antibiotics in the prevention and treatment of many primary cutaneous bacterial infections, particularly in dermatological care units and for the local treatments of 
superficial infections due to surgery, injury and abrasion, has not to be demonstrated anymore. Topical antibiotics are well-known for preventing the growth of pathogenic bacteria into wounds, therefore promoting faster healing and reducing care costs. However, some studies evidenced an increase of multidrug resistance in the microbial flora of the skin (as well as for many strains belonging to the a priori harmless Staphylococcus epidermidis species) that may become opportunistic pathogens causing infections, especially among patients with medical implants. ${ }^{7,9,10}$ The design of novel antimicrobial transdermal patches must therefore integrate this issue by using alternative antimicrobial agents/principles that can be used on either antibiotic-sensitive or resistant bacteria while preventing new resistances to emerge.

Antimicrobial hydrogels represent an attractive option due to their unique and tunable physicochemical properties, in particular their mechanical softness and flexibility. Antimicrobial hydrogels can be classified according to their specific mode of action against bacteria with a differentiation between release-killing and contact-killing hydrogels. The antimicrobial activity of the former is triggered by the release of antimicrobial agents (e.g. nanoparticles, antibiotics or bacterial viruses) embedded within the hydrogel matrix, whereas that of the latter originates from the functionalization of the hydrogel surface by means of antimicrobial molecules (e.g. peptides) or polymeric coatings of natural or synthetic origins. ${ }^{11 \text {, }}$ 12 Hydrogels are generally derived from bioinspired and/or manufactured hydrophilic polymers that are physically or chemically cross-linked, and their biocompatibility and likeness to living tissues open up many opportunities for biomedical applications. ${ }^{13-15}$ Hydrogels based-biotechnology is currently used in tissue engineering scaffolds, drug delivery systems and wound plasters. ${ }^{16,17}$

Due to their remarkable properties, hydrogels are suitable for skin infection treatment, medical implants coating and wound healing. ${ }^{17,}{ }^{18}$ In addition, antimicrobial hydrogels provide 
a moist environment around wounds, which improves the healing process by protecting the damaged skin from cellular dehydration and by favoring angiogenesis. Mechanical properties of hydrogels and their porosity can be easily controlled to facilitate channels formation, subsequent absorption of wound exudates and air circulation. ${ }^{19,20}$

Bacteria-killing viruses, so-called bacteriophages or phages, are viruses only targeting and killing bacteria. They are natural predators of bacteria, which positions them as promising candidates to serve as efficient alternatives to conventional antimicrobial agents and to achieve a sustainable therapeutic treatment against multidrug resistant bacteria. Phages belong to diverse groups of viruses-killing bacteria, ${ }^{21}$ and some of them offer the advantage to be very specific in terms of bacterial species targets, bacteria recognition processes, and to be easily cultivable, ${ }^{22}$ which paves the way to potential applications in biotechnology, ${ }^{23,} 24$ nanomedicine ${ }^{25,26}$ and nanotherapeutics. ${ }^{27,28}$ Phage medication, or phagotherapy for short, has been applied for decades to treat bacterial infections. ${ }^{29,}{ }^{30}$ However, with the advent of antibiotics during the second world war, phagotherapy has fallen into disuse. ${ }^{29,30}$ With the rise of antibiotic-resistant bacteria and the lack of new efficient molecules, phagotherapy is reverted to one of the most advanced and promising solutions. ${ }^{21,30}$

We recently evidenced that some hydrogels consisting of polyelectrolyte multilayers can host phages whose infectivity and virulence towards bacteria remain preserved. ${ }^{31}$ However, there remains a lot to be done for optimizing the performance of hydrogels and polymeric films to host phages $^{32,33}$ and for formulating antibacterial gels or biocoatings operational against specific target bacteria. Such devices truly constitute a breakthrough in biomaterials science and biotechnology, especially in the fields of implants and artificial joints as they may serve as sterile growth scaffold for human tissue. The development of transdermal drug delivery systems containing phages has also gained interests in agriculture, pharmaceutics, farming and food industries. ${ }^{26,} 34-36$ Spray drying, extrusion dripping, emulsification and 
polymerisation are among the methods that are most commonly used for encapsulation of phages in organic coatings. ${ }^{37-40}$ Despite of all these efforts, most of these processes still lead to a serious loss of- and/or reduction in- the bacteriolytic activity of bacteriophages once the latter are incorporated into the hosting organic matrix. ${ }^{31,40}$ To solve this issue and to propose operational bacteriophages-loaded hydrogels with full preservation of the native phages activity, the way physicochemical properties defining the hydrogel matrix affect the infectivity potential of the loaded phages should be addressed.

Along this line of thinking, we investigate here how the mechanical properties of polyelectrolyte multilayers-based hydrogels hosting viral particles impact on their antimicrobial performance and bacterial adhesion features. To this end, poly(allylamine hydrochloride) and hyaluronic acid were combined according to the layer-by-layer (LbL) method, leading to the production of a hydrogel, denoted as (PAH-HA), that we moderately or highly cross-linked prior to filling it with viral particles via passive diffusion. We selected two kinds of bacteria-killing viruses: $\varphi \mathrm{X} 174$, an icosahedral viral particle with $c a .30 \mathrm{~nm}$ diameter belonging to the Microviridae family, and T4, a $200 \mathrm{~nm}$ head-tailored phage belonging to the Myoviridae family. These phages are well known for specifically targeting Escherichia coli strains. Nanomechanical properties of the different synthetized hydrogels were addressed by spatially-resolved atomic force microscopy (AFM), while infectivity of the phages embedded in the hydrogel was quantified by means of the plaque-assay method. Anti-bacteria adhesion and antimicrobial performances of the phages-loaded (PAH-HA) matrix and of other polyelectrolyte multilayer hydrogels constructed with different polycation and polyanion building units, were further evaluated by conventional bioassays, including cell membrane integrity tests and counting of adhered bacterial cells. 


\section{Materials and methods}

\section{Chemicals and preparation of polyelectrolytes-based hydrogels.}

Tris(hydroxymethyl)aminomethane (TRIS, ref. T4661), sodium chloride (NaCl, ref. 1.06406.0500), poly(allylamine hydrochloride) $(\mathrm{PAH}, \mathrm{Mw}=50,000 \mathrm{~g} / \mathrm{mol}$, ref. 283223), poly(L-lysine hydrochloride) (PLL, Mw>30,000 g/mol, ref. P9404), poly(dimethyldiallylammonium chloride) (PDADMAC, $\mathrm{Mw}=400,000-500,000 \mathrm{~g} / \mathrm{mol}$, ref. 409030) and poly(acrylic acid sodium salt) (PAA, Mw 50,000 g/mol, ref. 00627) and poly(L-glutamic acid (PGA, Mw=50,000-100,000 g/mol, ref. P4886) were purchased from Sigma-Aldrich (France) and Polysciences (Biovalley, France). Sodium hyaluronate (HA, 301$450 \mathrm{kDa}$, ref. HA500K-1) was purchased from LifeCore Biomedical (Chaska, USA). Each polyelectrolyte was dissolved in buffer solution consisting of $150 \mathrm{mM} \mathrm{NaCl}$ and $10 \mathrm{mM}$ TRIS $(1 \mathrm{mg} / \mathrm{mL})$ with $\mathrm{pH}$ adjusted to 7.4. Chemical and antibacterial properties of each anionic and cationic polymer considered in this work are summarized in Table $\mathbf{1}$.

The automated sequential build-up of the multilayer hydrogels at room temperature $\left(22^{\circ} \mathrm{C}\right)$ was performed using borosilicate slides as supporting substrate in order to facilitate subsequent film analysis by atomic force microscopy (AFM). Hydrogels were constructed using a dipping robot (Riegler \& Kirstein GmbH, Berlin, Germany) according to the LbL method. ${ }^{41,} 42$ As far as the poly(allylamine hydrochloride)-hyaluronic acid hydrogel is concerned, the first deposited layer consisted of poly(allylamine hydrochloride) denoted as $\mathrm{PAH}$, and the sample was then rinsed by immersion for $5 \mathrm{~min}$ in the buffer solution $(150 \mathrm{mM}$ $\mathrm{NaCl}, 10 \mathrm{mM}$ TRIS, pH 7.4). Then, hyaluronic acid, denoted as HA, was deposited according to the procedure invoked above for the deposition of PAH polycations. This build up process was iterated via alternate deposition of the polycationic and polyanionic polymers until the hydrogel consisted of 30 bilayers. If not used immediately after construction, the (PAH-HA) hydrogels were stored at $4^{\circ} \mathrm{C}$ in the buffer solution. Subsequently, phages were loaded in the 
polyelectrolyte multilayers (PEM in short) via passive diffusion process as described elsewhere. ${ }^{31}$ Procedures for the production and purification of the here-adopted $\mathrm{T} 4$ and $\varphi \mathrm{X} 174$ bacteriophages are detailed in the next section. The above protocol was adopted for the construction and phages-filling of (PDADMAC-PAA), (PLL-HA), (PAH-PGA) and (PAH-PAA) hydrogels.

\section{Chemical cross-linking and thickness evaluation of PAH-HA hydrogels}

Chemical cross-linking of the (PAH/HA) hydrogel was performed following the protocol detailed elsewhere. ${ }^{43,44}$ Briefly, chemical stiffening of the hydrogel is based on the reaction between formerly activated HA carboxylic sites and PAH primary amine groups in the presence of a water-soluble carbodiimide (EDC) and N-hydroxysuccinimide (NHS), both purchased from Sigma. EDC was dissolved in a buffer solution (150 mM NaCl, $10 \mathrm{mM}$ TRIS, $\mathrm{pH}$ 5.0) at various final concentrations varying from 1 to $50 \mathrm{mg} / \mathrm{mL}$. NHS was dissolved in the same buffer solution at a final constant concentration of $20 \mathrm{mg} / \mathrm{mL}$. The (PAH/HA) hydrogels built onto glass slides were introduced in 24-well culture plates and set in contact with $1 \mathrm{~mL}$ of the EDC/NHS mixture during $18 \mathrm{~h}$ at $4{ }^{\circ} \mathrm{C}$. Then, hydrogels were rinsed three times during 30 minutes with a buffer solution (150 mM NaCl, $10 \mathrm{mM}$ TRIS, pH 8.0). Finally, cross-linked hydrogels were stored in 24-well culture plates containing $1 \mathrm{~mL}$ of initial buffer solution (150 mM NaCl, $10 \mathrm{mM}$ TRIS, $\mathrm{pH}$ 7.4) prior to bacteriophages loading, microbial assays and AFM experiments.

Hydrogels thickness was evaluated by AFM imaging of 3 areas $\left(40 \times 40 \mu \mathrm{m}^{2}\right)$ previously scratched with a needle. The thickness was estimated from the difference between the top height of the hydrogels and that of the supporting flat glass substrate (serving as the reference) along the scratched line. 


\section{Production and purification of bacteriophages.}

The production of the bacteriophages of interest in this work requires host bacteria: E. coli $\mathrm{B}$ (strain number ATCC 11303) for T4 (ATCC 11303-B4) and E. coli C (ATCC 13706) for $\varphi \mathrm{X} 174$ (ATCC 13706-B1). T4 and $\varphi$ X174 phages were replicated according to the ISO 10705-2 procedure, without the chloroform lysis step. The latter was not considered in order to (i) limit the presence of incomplete viral particles originating from chloroform-induced lysis of bacteria, and (ii) to avoid the selection of the only polar viruses, recalling that most apolar viruses may interact with chloroform and they may thus be eliminated together with this solvent. ${ }^{45}$ After replication, phage suspensions were centrifugated (Beck man [Fullerton, CA] model $\mathrm{J} 2-22 ; 10,000 \mathrm{~g} ; 10 \mathrm{~min} ; 4^{\circ} \mathrm{C}$ ) and the supernatant was filtered using a $0.22 \mu \mathrm{m}$ membrane (Millex®-GP Millipore). Then, $30 \mathrm{~mL}$ of this suspension was concentrated in 5.5 mL by Amicon Ultra-15 (PLHK, membrane Ultracel-PL, $100 \mathrm{kDa}$ ). The phage suspensions were purified by cesium chloride gradient after addition of $3.8 \mathrm{~g} \mathrm{CsCl}$ and centrifugation at $29,000 \mathrm{~g}$ for $18 \mathrm{~h}$ at $15^{\circ} \mathrm{C}$. About $1.5 \mathrm{~mL}$ of phage suspension was extracted from central strip and then purified by dialysis $(100 \mathrm{kDa}$ molecular weight cutoff, Spectrum [Gadena, CA Spectrum Labs]), first against de-ionized water for $14 \mathrm{~h}$, and then against $1 \mathrm{mM} \mathrm{NaCl}$ at $\mathrm{pH} 7$ \pm 0.3 for $14 \mathrm{~h}$. The obtained concentrations of phages following this protocol ranged from $10^{9}$ to $10^{11}$ plaque forming unit (PFU) per $\mathrm{mL}$.

\section{Infectivity of the bacteriophages loaded in the hydrogels.}

As the thickness of all investigated hydrogels is basically identical $(2.7-3.8 \mu \mathrm{m})$, results pertaining to virus concentrations in the hydrogels were simply expressed here in PFU units in order to facilitate data comparison and avoid normalization by hydrogel volume/area. The evaluation of the amount of the only infective phages in the hydrogels was performed via plaque bioassays, which basically consists in counting clear bacteria lysis-formed plaques 
upon spotting the phages originating from the inoculum solution or from the dissolved hydrogels on a lawn of E. coli cells after 24 hours incubation, as described by the ISO 107052 procedure. More specifically, the amount of infective phages stored within the hydrogels was quantified upon application of bioassays method to the originally phage-containing hydrogels after their complete dissolution by osmotic shock in a $2 \mathrm{M} \mathrm{NaCl}$ buffer solution.

\section{Bacterial growth and samples preparation}

E. coli $\mathrm{B}$ and $E$. coli $\mathrm{C}$ were pre-grown for $16 \mathrm{~h}$ at $37^{\circ} \mathrm{C}$ under agitation $(150 \mathrm{rpm})$ in LuriaBertani (LB) broth. The next day, $25 \mathrm{~mL}$ of fresh LB medium was inoculated with about 200 $\mu \mathrm{L}$ of the previous culture and cultivated under the same conditions until the biomass reached an optical density at $600 \mathrm{~nm}\left(\mathrm{OD}_{600}\right)$ of 0.5 . Then, $1 \mathrm{~mL}$ of the bacterial suspension was added in each well of the 24-well culture plates containing the hydrogel substrates. The 24-well culture plates were incubated at $25^{\circ} \mathrm{C}$ without any agitation for 4 hours, which slows down bacteria physiology and phage infectious cycle, allowing the detection of bacterial membrane alteration prior to occurrence of cell lysis induced by phages infection. Afterwards, each well was emptied using a micropipette and samples were rinsed three times with $1 \mathrm{~mL}$ PBS solution to remove bacteria non-adhered to the hydrogel, prior to bacterial membrane integrity and bacterial counting assays.

\section{Fluorescence optical microscopy and bacterial membrane integrity assays.}

Bacterial membrane integrity was assessed with BacLight ${ }^{\mathrm{TM}}$ stain kit (L7012, Molecular Probes, Eugene, USA). Cell wall permeability of bacteria set in contact during 4 hours at $25^{\circ} \mathrm{C}$ with phages in the LB medium was examined according to the methodology detailed in previous studies and compared to that in the absence of bacteriophages. ${ }^{46,47}$ These incubations conditions allow phages to efficiently attach to bacteria and damage their membrane, but they 
do not make it possible a proper achievement of phages infectious cycle (and accompanying cell lysis with a release of replicated viruses). With the BacLight ${ }^{\mathrm{TM}}$ stain kit, bacteria with intact membranes exhibit green fluorescence (Syto 9 labelling) whereas bacteria with damaged membranes show red fluorescence (propidium iodide, PI, labelling). The bacteria adhered to the different hydrogel substrates were stained with $B a c$ Light $^{\mathrm{TM}}$ kit during 20 minutes under dark conditions. Then, the samples were rinsed with sterile PBS buffer solution $(\mathrm{pH}$ 7.4) to eliminate the excess of dyes, and then fixed with a solution of glutaraldehyde at $2 \%$ in PBS for 30 minutes. Subsequently, samples were set in BacLight ${ }^{\mathrm{TM}}$ mounting oil environment as described by instructions by the manufacturer. Images with green and red fluorescence emissions were acquired simultaneously with the $\times 100$ oil immersion objective of an Olympus BX51 microscope equipped with an Olympus XC50 camera.

\section{Confocal Laser Scanning Microscopy (CLSM) and Scanning Electron Microscopy (SEM)}

Phage loading into hydrogels was monitored by Confocal laser scanning microscopy (CLSM) measurements. CLSM-based observations were carried out with a Zeiss LSM 510 microscope using a $\times 40 / 1.4$ oil immersion objective and with $0.4 \mathrm{~mm}$ z-section intervals. Sybr Gold ${ }^{\mathrm{TM}}$ fluorescence was detected after excitation at $495 \mathrm{~nm}$ with a cutoff dichroic mirror $488 \mathrm{~nm}$ and an emission band-pass filter 505-530 nm (green). Rhodamine fluorescence was detected after excitation at $543 \mathrm{~nm}$, dichroic mirror $543 \mathrm{~nm}$, and emission long pass filter $585 \mathrm{~nm}$ (red). An average of four images $(512 \times 512$ pixels $)$ in the same location were acquired at. Virtual hydrogel section images were performed in PBS buffer solution at $\mathrm{pH}$ 7.4. Phages were stained with Sybr Gold ${ }^{\mathrm{TM}}$ dye according to staining protocol detailed elsewhere ${ }^{48,49}$ prior to monitor their diffusion through the hydrogels. The latter were stained in red by immersing the hydrogel in a solution of PAH/PAH-rhodamine (95:5) at $1 \mathrm{mg} / \mathrm{mL}$ in $(\mathrm{NaCl}$, Tris) buffer 
during 10 minutes. Then hydrogels were extensively rinsed with PBS buffer solution before imaging by CLSM.

Morphology and porosity of hydrogels were addressed by classical, high-vacuum scanning electron microscopy (SEM). All micrographs were carried out using a JSM-IT500 HR combined with EDS Ultim® Max $170 \mathrm{~mm}^{2}$ (Jeol, France). SEM can be applied only to dry, conductive specimens in vacuum. Therefore, hydrogel samples were previously dried overnight under vacuum and then coated with a $5 \mathrm{~nm}$ gold layer using a sputter coater (Milexia, K575 Turbo Q150T S, France). The micrographs were obtained for an accelerating voltage of $10 \mathrm{kV}$ at $20^{\circ} \mathrm{C}$ under high vacuum.

\section{Atomic Force Microscopy (AFM).}

AFM images and force spectroscopy measurements were recorded in liquid using a Bioscope Resolve (Bruker Nano Surface, Bruker France SAS, Palaiseau, France) and a MFP3D-BIO instrument (Asylum Research Technology, Oxford Instruments Company, Wiesbaden, Germany), respectively. Morphology of the hydrogel was investigated by AFM operating in contact mode in aqueous environment. Silicon nitride cantilevers of conical shape purchased from Bruker (MLCT, Bruker France SAS, Palaiseau, France) with spring constant of $c a .9-14$ $\mathrm{pN} / \mathrm{nm}$ were used for both hydrogel imaging and nanomechanical measurements. At least 5 images per sample condition were recorded with a resolution of $512 \times 512$ pixels and a scan rate of $1 \mathrm{~Hz}$. Nanomechanical properties of the hydrogels were monitored in PBS buffer solution (pH 7.4) by recording at least 3 Force-Volume Images (FVI) at different locations of the samples. Each FVI consisted of a grid of $32 \times 32$ force curves measured with adopting a 2 $\mu \mathrm{m} . \mathrm{s}^{-1}$ approach rate of the tip toward the sample. The Young modulus $E$ was evaluated by analyzing the force-indentation curves on the basis of the Sneddon model. ${ }^{50,51}$ According to the latter, the Young modulus is related to the applied force via the equation: 


$$
F=\frac{2 E \cdot \operatorname{Tan}(\alpha)}{\pi\left(1-v^{2}\right)} R^{1 / 2} \delta^{2} \cdot f_{\mathrm{BECC}}
$$

, where $\delta$ is the indentation depth, $v$ the Poisson coefficient, $\alpha$ the semi-top angle of the conical tip and $f_{\mathrm{BECC}}$ is the bottom effect cone-correction function that takes into account the stiffness of the glass substrate that supports the polyelectrolytes-based hydrogel. All FVI were analyzed using a home-made Matlab program detailed elsewhere, ${ }^{52}$ and the average Young moduli values given in this work were derived from analysis of at least 3072 force curves.

\section{Results and discussion}

\section{Physicochemical characterization of (PAH-HA) hydrogels.}

(PAH-HA) hydrogel consisting of 30 bilayers was built-up according to LbL method with association of PAH and HA, subsequently cross-linked (or not) with EDC/NHS at several concentrations $(1,2,5,10$ and $50 \mathrm{mg} / \mathrm{mL}$ in EDC) as briefly described in scheme 1 . At such concentrations, all crosslinking reagents (EDC/NHS) are completely consumed by the coupling reaction, and an extensive rinsing step was performed prior to physicochemical investigations and microbial assays. ${ }^{53}$ The goal of our work is to design a new type of antimicrobial hydrogel acting by phagotherapy. One advantage of using phagotherapy lies in the 'snowball effect' that is achieved as several new viral particles (up to 200) may be released in the medium by a single infected and lysed bacterium, with each of these newly generated viruses being able to carry out a new infection. In this way, hydrogels have to be loaded with a sufficient initial amount of phages so as to initiate infection of adhered bacteria and/or planktonic ones, and a subsequent snowball effect via release of phages from the targeted infected bacteria, as described in scheme $\mathbf{1}$.

Before loading the phages in the hydrogel matrix, analyses of the morphology of native and cross-linked hydrogels were addressed by AFM (Figure 1), which includes the evaluation of 
the hydrogel thickness and that of the root mean square (rms) surface roughness (Figures S1S2). AFM images basically evidence homogeneous surfaces for native hydrogels that feature few irregularities only, and they show the presence of few bumps at the surface of the hydrogels that were cross-linked (Figure 1). Surface roughness of the native and moderately cross-linked (PAH-HA) hydrogels is basically constant (ca. 10-15 nm) and it increases up to $\sim 40 \mathrm{~nm}$ with increasing cross-linker concentration from 2 to $50 \mathrm{mg} / \mathrm{mL}$ (Figure S1). In addition, the thickness of the (PAH-HA) hydrogels slightly decreases from $c a .3 .8 \mu \mathrm{m}$ to 2.7 $\mu \mathrm{m}$ with increasing cross-linker concentration from 0 to $50 \mathrm{mg} / \mathrm{mL}$ (Figures S1-S2). This shrinking property of the hydrogels is well documented in literature and it is the result of the formation of chemical bonds and reduction of polymer mesh and network size. ${ }^{18,54}$ It further suggests a stiffening of the hydrogels with increasing the extent of chemical cross-linking. Careful inspection of SEM micrographs carried out on the edge of the hydrogels does not show any significant difference in terms of porosity (Figure S3). The cottony and layered appearance seems to be preserved over the entire thickness of the hydrogels regardless of the degree of crosslinking/stiffening. These SEM observations could originate from the drying process of the hydrogel, as required for SEM imaging, which in turn leads to materials shrinking. In this way, the porosity of the hydrogels should be proportional to their corresponding swelling ratio and follow.

To quantify the hydrogels stiffening, their nanomechanical properties were addressed by AFM according to the nanoindentation method (Figure 2a). ${ }^{55}$ In line with anticipation, hydrogel stiffness is strongly impacted by chemical cross-linking with a resulting elasticity that increases linearly with increasing cross-linker concentration from 0 to $10 \mathrm{mg} / \mathrm{mL}$, and it levels off at sufficiently large concentrations before reaching a plateau value at $c a .40 \mathrm{mg} / \mathrm{mL}$. Overall, this increase in hydrogel elasticity amounts to $20 \mathrm{kPa}$ up to $700 \mathrm{kPa}$ for EDC concentrations in the range 0 to $50 \mathrm{mg} / \mathrm{mL}$. Such qualitative dependence of material stiffness 
on chemical cross-linking has been extensively reported for polyelectrolyte multilayer films and other polymer-based hydrogels. ${ }^{53,56,57}$ Indeed, the 3D porous structure of the hydrogels should be significantly reduced with chemical crosslinking. Such structural modifications are qualitatively measurable through the hydrogel swelling ratio (Figure $\mathbf{2 b}$ ) which corresponds to the compactness and reflect void fraction over the total hydrogel volume. These results evidenced a decrease by a factor of 3 of hydrogel swelling ratio when hydrogel stiffness is increased by a factor of 35. The here-evidenced 35-fold increase in Young modulus concomitantly to a 3-fold decrease in swelling ratio of (PAH-HA) hydrogel, from its native form to that of a highly cross-linked hydrogel, is expected a priori to impact on the diffusion properties of viral nanoparticles during their loading phase. To address this point on a quantitative basis, phages loading kinetics and phages-storage capacity of the hydrogels were estimated along the lines detailed in the next section.

\section{Impact of hydrogel chemical cross-linking on loading kinetics of viral particles and on} phages storage capacity.

To evaluate the effect of hydrogel stiffness on viral particles absorption, we incubated the polyelectrolyte multilayer (PAH-HA) film, defined by different extents of chemical crosslinking, for 24 hours in a $1 \mathrm{~mL}$ buffer solution containing the bacteriophages, either $\varphi \mathrm{X} 174$ (icosahedral viral particle with $c a .30 \mathrm{~nm}$ diameter) or T4 phages (200 nm head-tailored phage) at $\sim 2.4 \times 10^{7}$ and $\sim 2.7 \times 10^{7} \mathrm{PFU} / \mathrm{mL}$, respectively. Effective loading of phages within hydrogels has been already described in our previous work. ${ }^{31}$ The presence of phages inside hydrogels volume is clearly confirmed by fluorescence-based observations using CLSM (as illustrated by Figure S4). We emphasize that no phages were located/observed at the extreme surface, as judged by SEM micrographs reported in Figure S5. These observations strongly support CLSM measurement confirming that phages should be rather located within the 
hydrogels. The evaluation of the amount of infective phages within the hydrogel matrix was performed by plaque bioassay method at different stages of the phages loading procedure (Figure 3a). The results show that the amount of viral particles loaded in the (PAH-HA) hydrogel increases with time and reaches a plateau after 4-6 hours contact with the viral inoculum, regardless of the nature of the bacteriophage considered. Surprisingly, neither the rate of phages entrapment nor the maximal storage capacity of the hydrogel significantly depends on the size and geometry of the bacteriophages (that differ for $\varphi \mathrm{X} 174$ and T4 phages). Quantitatively, $20 \%$ of the $\varphi \mathrm{X} 174$ or T4 infective viral particles in initial contact with (PAH-HA) hydrogel were entrapped after 24 hours, and the loading rates (evaluated in the linear, short-term part of the curves displayed in Figure 3a) were $(0.62 \pm 0.21) \times 10^{6}$ viruses/h and $(0.68 \pm 0.22) \times 10^{6}$ viruses/h for $\varphi$ X174 and T4, respectively. Such invariance in the amount of entrapped viral particles with respect to phages geometry was also reported for H387 (Siphoviridae) and A511 phages (Myoviridae) and other coliphages loaded into alginate and polysaccharidic hydrogels. ${ }^{58,} 59$ In these previous studies, however, bacteria were immobilized into- or at- the hydrogel surface prior to phage production and incorporation in the matrix, whereas, here, hydrogels surface was exposed to suspensions of viruses produced beforehand (scheme 1).

In Figure 3b, we report the maximal $\varphi \mathrm{X} 174$ and $\mathrm{T} 4$ phages storage capacity of the hydrogels as a function of hydrogel mechanical stiffness determined by AFM. Figure $3 \mathbf{b}$ evidences the absence of significant impact of hydrogel stiffness on phages-storage capacity: no matter whether the hydrogel is cross-linked or not, the total amount of phages it may host remains essentially the same. Closer inspection of Figure 3b suggests that stiffness tends to slightly improve $\varphi \mathrm{X} 174$ phages storage as compared to that of the larger T4 phages, but this effect is, within experimental error, mostly restricted to the only low cross-linker concentrations range tested in this work. A marked differentiated steric-mediated diffusional loading of T4 phages 
and of the significantly smaller $\varphi \mathrm{X} 174$ phages may have been anticipated with varying hydrogel stiffness, the latter reflecting changes in pore size of the matrix due to covalent bonds between PAH and HA polymers. However, apparently, this process is not significantly at stake for $\varphi$ X174 and T4 phages, and it does not play a dominant role in defining the performance of the hydrogel in its capacity to host $\varphi$ X174 and T4 phages.

\section{Influence of hydrogel stiffness on bacterial adhesion and cell wall integrity (in the}

\section{absence of phages).}

Prior to evaluating the respective antimicrobial activities of the different phages-loaded hydrogels of interest in this work, we systematically addressed their adhesive properties towards the bacterial cells to be targeted and killed by the viruses hosted in the hydrogels $(E$. coli $\mathrm{B}$ and $E$. coli $\mathrm{C}$ for $\mathrm{T} 4$ and $\varphi \mathrm{X} 174$ phages, respectively). For that purpose, we incubated the different hydrogels (without embedded bacteriophages) for 4 hours in $1 \mathrm{~mL}$ suspension of E. coli $\mathrm{B}$ and $E$. coli $\mathrm{C}$ with optical density at $600 \mathrm{~nm}$ of about 0.5 (corresponding to $c a$. $10^{8}$ bacteria, Figure S6). Then, after rinsing, samples were stained with the Baclight $^{\mathrm{TM}}$ viability test for the counting of adhered and/or damaged bacteria (note that damaged bacteria may be still alive) as a function of (PAH-HA) hydrogel stiffness (Figure 4 and see related raw epifluorescence data in Figure S7). The results evidence that the concentration of bacterial cells adhered at the hydrogel surface increases linearly with hydrogel stiffness and this finding holds for both E. coli $\mathrm{B}$ and $E$. coli $\mathrm{C}$ strains. The surface concentrations of adhered E. coli B and $E$. coli $C$ are $(0.9 \pm 0.3) \times 10^{6}$ and $(1.8 \pm 0.7) \times 10^{6}$ cells $/ \mathrm{cm}^{2}$, respectively, for the native (PAH-HA) hydrogel with ca. $20 \mathrm{kPa}$ Young modulus, and these concentrations increase up to $(45.3 \pm 13.1) \times 10^{6}$ and $(47.0 \pm 17.4) \times 10^{6}$ cells $/ \mathrm{cm}^{2}$ for highly cross-linked hydrogels with stiffness of ca. $700 \mathrm{kPa}$ (Figure 4a). Between $1 \%$ and $5 \%$ of the total amount of bacteria initially in contact with native or slightly cross-linked hydrogels were able to adhere onto the 
hydrogel surface after 4 hours incubation time. Conversely, between $c a .25 \%$ and $60 \%$ of the initial amounts of cells were detected on the surface of the highly cross-linked hydrogels after 4 hours incubation. Besides, when the hydrogel stiffness is increased from $20 \mathrm{kPa}$ to $700 \mathrm{kPa}$, we systematically observe an increase in the number of adhered bacteria by a factor of $25-50$ depending on the bacterial strain. Such positive correlation between bacterial adhesion and stiffness of the substrate has been reported in literature for E. coli and others bacterial strains including Pseudoalteromonas sp. and Pseudomonas aeruginosa. ${ }^{60-62}$ It can be explained by bacterial mechanosensing processes ${ }^{61-63}$ Bacterial mechanosensing is a commonly admitted phenomenon involved in substrate stiffness dependent-adhesion. ${ }^{64,}{ }^{65}$ Enhancement or reduction of bacterial adhesion with increasing substrate stiffness is strongly dependent, among other factors, on the bacterial strain considered and on the types/densities of mechanosensors decorating its cell wall. These sensors triggering bacterial responses are involved in many signaling processes, however, very little is known about the molecular pathways leading to substrate stiffness-dependent bacterial adhesion.

The impact of (PAH-HA) hydrogel stiffness on the integrity of membranes of adhered bacteria is shown in Figure $\mathbf{4 b}$. The data evidence a dramatic increase in the surface concentration of adhered bacteria that feature altered membranes with decreasing hydrogel stiffness: $c a .60 \%$ of the adhered E. coli $\mathrm{B}$ and $E$. coli $\mathrm{C}$ exhibit a significant membrane permeabilization when in contact with native or weakly cross-linked hydrogels, to be compared with the only few percents of damaged cells adhered at the surface of highly crosslinked hydrogels. Combining data of Figure $\mathbf{4 a}$ and $\mathbf{4 b}$ reveals that the surface amount of bacteria with damaged membrane increases with decreasing hydrogel stiffness. This result suggests that the antimicrobial activity of the hydrogel in the absence of phages, as viewed by the prism of cell membrane integrity loss, should be related to the mobility of free PAH chains as this mobility necessarily decreases with increasing the extent of chemical cross- 
linking in the hydrogel. ${ }^{66,} 67$ This hypothesis is supported by the fact that PAH is a polycationic polymer able to destabilize and permeabilize the outer membrane of bacteria, and that it exhibits antimicrobial activity against $E$. coli $\mathrm{B}$ and $E$. coli $\mathrm{C}$ with minimal inhibitory concentration $\left(\mathrm{MIC}_{100}\right)$ of about 0.04 and $0.05 \mathrm{mg} / \mathrm{mL}$, respectively (Table 1). ${ }^{31,67,68}$ Altogether, the above results demonstrate that an increase in the stiffness of (PAH-HA) hydrogel significantly promotes bacterial adhesion but dramatically reduces the intrinsic antibacterial activity of the hydrogel that originates from sufficiently mobile polycationic chains. Native or weakly cross-linked (PAH-HA) hydrogels feature a significant antimicrobial activity in the absence of bacteriophages and this activity leads to a permeabilization of bacterial membrane triggered by free or sufficiently mobile polycationic PAH chains. The impacts of loaded phages on these antimicrobial properties of (PAH-HA) hydrogels are examined in the following section.

\section{Antimicrobial activity of hydrogels hosting bacteria-killing viruses.}

To evaluate the antimicrobial performance of (PAH-HA) hydrogels loaded with T4 or $\varphi$ X174 phages, BacLight ${ }^{\mathrm{TM}}$ assays were performed on bacteria after 4 hours incubation of the bacteriophages-loaded hydrogels in suspensions initially containing $c a .10^{8}$ bacteria. The analysis of the concentrations of bacteria adhered onto the phages-loaded hydrogels with increasing hydrogel stiffness (Figure 5) reveals two different behaviors depending on the nature of the hosted phages (Figures 5a and 5b relevant for $\mathrm{T} 4$ and $\varphi \mathrm{X} 174$ phages, respectively). This finding is further supported by Figure S8 that displays the dependence of the surface concentration of the two bacterial strains of interest onto the native and crosslinked (PAH-HA) hydrogels in the absence and presence of T4 and $\varphi$ X174 phages loaded therein. In detail, the surface concentration of adhered bacteria on T4-loaded (PAH-HA) hydrogel increases with increasing hydrogel stiffness, which qualitatively conforms to the 
results given in Figure 4 for the situation where phages were not embedded in the hydrogel. Quantitatively, with increasing hydrogel stiffness from $20 \mathrm{kPa}$ to $700 \mathrm{kPa}$, the presence of T4 phages leads to a reduction of $c a .50-60 \%$ down to $20 \%$ of the amount of adhered bacteria determined in the absence of phages in the hydrogel. Similarly to T4-loaded hydrogels, bacterial adhesion on $\varphi$ X174-loaded (PAH-HA) system increases with hydrogel stiffness. However, the noticeable difference is that the loaded $\varphi \mathrm{X} 174$ phages leads to a more significant decrease of the surface concentration of adhered cells, by $70 \%$ to $80 \%$, over the whole range of Young moduli tested. Recalling that these findings cannot be rationalized by possible differences in the concentrations of $\mathrm{T} 4$ and $\varphi \mathrm{X} 174$ phages loaded in the hydrogels (Figure 3), Figure 5 reveals instead distinct infectivity patterns of the loaded-phages depending on their very nature. This result does not stem from differences in the virusbacteria recognition process because both $\mathrm{T} 4$ and $\varphi \mathrm{X} 174$ viral particles are able to recognize specifically LPS and porin OmpC from E. coli. ${ }^{69,70}$ It is more likely explained by the longer replication time (and resulting lower intrinsic lytic activity) of $\mathrm{T} 4$ phage as compared to that of $\varphi$ X174 phage..$^{71-73}$ Accordingly, the bacteriolytic 'snowball effect' mentioned earlier is probably achieved for $\varphi$ X174 phages loaded-hydrogels, in line with the dramatic reduction in the concentration of the adhered cells observed in Figure $\mathbf{5 b}$, whereas this effect is not much operational for T4 phages loaded-hydrogels. Furthermore, control experiments performed on the native (PAH-HA) hydrogel (i.e. not cross-linked) evidenced that only $10 \%$ of the phages initially entrapped are released over 2 hours and there is no additional phage release at longer times, when the hydrogel was immersed in a pure $150 \mathrm{mM} \mathrm{NaCl}$ solution (Figure S9). We recall that antimicrobial performances of the phages-loaded hydrogels were evaluated on the basis of co-incubation experiments with bacteria for 4 hours. Therefore, given the small amount of $\varphi \mathrm{X} 174$ released from the hydrogel and $c a$. two-fold decrease of the number of bacteria adhered at the hydrogel surface when hosting phages, the duration of our co- 
incubation experiments is probably in line with the beginning of the snowball effect previously mentioned for $\varphi$ X174. The differentiated dependences of the reduction in adhered bacteria concentration on hydrogel stiffness for both phages are discussed in the following alinea in terms of antimicrobial activity of the phage-loaded hydrogels. We emphasize that the lytic activity of T4 and $\varphi$ X174 viral particles strongly depends on the temperature and the growth state of bacteria. Conditions where temperatures are lower than $37^{\circ} \mathrm{C}$ and bacteria are in stationary phase, as adopted here, tend to delay the lytic activity up to several hours. ${ }^{74-76}$ Consequently, increasing temperature and increasing the 4 hours delay (condition tested in this work) of incubation of the phages-loaded hydrogels with the bacteria would likely enhance the trends observed in Figure 5. It is expected that the addition of phages within the hydrogels would impact the mechanical properties of the latter. Many studies related to the mechanical characterization of hydrogels evidenced indeed that the presence of e.g. nanoparticles therein, even at low concentrations, leads to an increase in the material stiffness. ${ }^{77-80}$ Given this element and reasoning on the basis of our results (see Figure 4a), the stiffening of the hydrogels due to the addition of phages should promote the further adhesion of the bacteria as compared to scenarios where hydrogels are devoid of phages. However, our results clearly evidenced a significant decrease of the number of adhered bacteria (depending on the type of phage investigated) when comparing situations where hydrogels are loaded or not with phages (Figure 5). This argument clearly strengthens our conclusions according to which the antibacterial activity of the phages-loaded hydrogels is more important than that of their phages-lacking equivalents.

We now refine the above conclusions regarding the antimicrobial activity of phages-loaded hydrogels with different hydrogel stiffness by detailing (and discriminating) the activity against the bacteria located in the supernatant and the activity against the cells adhered at the very hydrogel surface (see scheme 1). We defined both types of activities as unity minus the 
ratio between the amounts of bacteria (either adhered at the hydrogel surface or located in the supernatant) detected after $4 \mathrm{~h}$ incubation in the presence and absence of phages. Antimicrobial activity against adhered bacteria therefore simply corresponds to unity minus the ratio of the data depicted in Figure 5 ["1-(blue over red points)'"]. With respect to antimicrobial activity against planktonic cells, its estimate accounts for the bacterial growth in the liquid medium above the surface of the hydrogels free of phages. Evaluation of the latter is based on the monitoring of the optical density of the supernatant covering the different cross-linked (PAH-HA) hydrogels (Figure S10) and by using the established calibration curves that relate optical density at $600 \mathrm{~nm}$ and bacterial cells concentration (Figure S6). We recall here that a small amount of the phages initially entrapped are released over the duration of the experiments (Figure S9). Consequently, the data reported in Figure 6 report the only contribution of the phages on the overall antimicrobial activity of the phages-loaded hydrogels. It is stressed that the amount of adhered bacteria or amount of bacteria in the supernatant considered for the antimicrobial activity calculations encompass both damaged and undamaged cells. The antimicrobial activity of T4-loaded hydrogel against adhered $E$. coli B significantly decreases over the range of examined stiffness values (Figure 6a), which is in line with the poor capability of T4 phages for reducing significantly the amount of adhered cells with increasing hydrogel stiffness (Figure 5a). In contrast, the antimicrobial activity of $\varphi$ X174-loaded hydrogels (Figure 6b) against adhered E. coli C barely depends on hydrogel stiffness and it amounts to $c a$. $70 \%$ to $80 \%$. This property may be explained by the fact that the pronounced lytic activity of $\varphi$ X174, favored by its short replication time compared to that of $\mathrm{T} 4$, remains unaffected by any role the hydrogel may play in fragilizing cells (see Figure 4b) and in rendering them more prone to infection and lysis after contact with phages. In other words, the efficient killing power of $\varphi$ X174, catalysed by the 'snowball effect', makes its lytic action basically independent of the hydrogel physicochemical 
environment. Unlike the bacteriolytic action of $\varphi \mathrm{X} 174$, that of T4 is significantly impacted by the hydrogel stiffness. Its delayed replication makes it more sensitive to the way the hydrogel modifies cell membrane integrity and, thereby, diminishes cell defense barrier against viral attack. The larger is the hydrogel stiffness, the least bacteria are damaged in the absence of phages (Figure $\mathbf{4 b}$ ), and thus the lesser becomes the antibacterial activity of the phages embedded in the hydrogel (Figure 6a). Similar qualitative trends are observed for the antimicrobial activity of T4- and $\varphi$ X174-loaded hydrogels against bacteria in the supernatant (Figures 6a and $\mathbf{6 b}$, respectively) as a function of hydrogel stiffness. Except for T4-loaded hydrogels with stiffness lower than $100 \mathrm{kPa}$, this antimicrobial activity is systematically lower than (or equal to) that against adhered bacteria ( $\mathrm{ca} .35 \%$ to $10 \%$ against planktonic E. coli $\mathrm{B}$ and $60 \%$ to $45 \%$ against planktonic $E$. coli $\mathrm{C}$ in the supernatant covering the different hydrogels). The very design of the biomaterial makes its contact-killing capabilities more efficient than its release-killing action even though the latter is by far not negligible. At this stage of the analysis, it is important to realize that the reduction of the amount of bacteria in the supernatant may partly relate to the release of bacteria-killing viruses from the hydrogel phase, even if it is not that significant (see Figure S9) and from the production of viruses following the infection of adhered cells (scheme 1), which is particularly true for $\varphi$ X174loaded hydrogels (Figure 6b). Obviously, our results demonstrate that the very contribution of the hydrogel surface in killing bacteria, regardless of the presence or absence of phages, is essential for a full apprehension of the overall antimicrobial activity of the phages-loaded hydrogels where both phages and hosting hydrogel environment contribute to bacteriolytic actions. The cells membrane integrity assays reported in Figure S11 demonstrate that bacteria adhered at the surface of native or weakly cross-linked (PAH-HA) hydrogels can be damaged without any contact with the bacteria-killing viruses for the reasons invoked when commenting Figure $\mathbf{4 b}$ ( $c f$. bacteriolytic activity of peripheral free polycationic chains of the 
hydrogels). It is noticed that the amount of bacteria exhibiting a damaged membrane is systematically higher for hydrogels hosting phages when the stiffness is larger than $200 \mathrm{kPa}$, thereby evidencing the important lytic activity contribution of the phages hosted within the hydrogels. This contribution counterbalances the poor bactericidal activity of the polycationic chains at such high hydrogel stiffness that significantly reduces the mobility, and therewith, the lytic action of polycationic chains (see Figure $\mathbf{4 b}$ ).

All results discussed so far clearly show that the substrate stiffness is an important factor to be considered for a proper design of coatings with efficient antimicrobial properties. To strengthen the above demonstration based on (PAH-HA) hydrogels whose stiffness is tuned by playing on chemical cross-linking conditions, we now report on antimicrobial activities of T4- and $\varphi$ X174-hydrogels (not cross-linked) that differ with respect to the nature of their polycation and polyanion building units and in terms of stiffness (Figure S12a). The native (i.e. not cross-linked) hydrogels considered were 30 bilayers-containing (PLL-HA), (PDADMAC-PAA), (PAH-PGA), and (PAH-PAA) hydrogels and the reader is referred to Table 1 for further information on the polycations and polyanions used, especially on their respective $\mathrm{MIC}_{100}$ values (if relevant). Figures $\mathbf{7 a}$ and $\mathbf{7 b}$ report the antimicrobial activity against adhered $E$. coli $\mathrm{B}$ and $E$. coli $\mathrm{C}$ (as defined along the lines detailed in the preceding developments), respectively, for these 4 polyelectrolyte multilayer films loaded with T4 and $\varphi \mathrm{X} 174$ phages. For the sake of comparison, results are provided together with those discussed earlier for native and cross-linked (PAH-HA) hydrogels hosting T4 and $\varphi$ X174 phages. Figure 7a evidences that the dependence of $\mathrm{T} 4$ antimicrobial activity data collected for the various T4-loaded hydrogels tested on hydrogel stiffness, elegantly falls within one single bell-shaped master curve exhibiting a maximum at $c a .50-100 \mathrm{kPa}$. Whereas the origin of the descending branch of this curve, located at the right side of the maximum for stiffness larger than 50-100 $\mathrm{kPa}$, was commented earlier on the sole basis of (PAH-HA) hydrogel results 
(Figure 6a), the ascending part of the curve (from ca. 10 to $50-100 \mathrm{kPa}$ ) reveals a new feature: with decreasing hydrogel Young modulus from $50-100 \mathrm{kPa}$ to $c a$. $10 \mathrm{kPa}$, the antimicrobial activity of T4-loaded hydrogels decreases. This finding relates to the inhibition of the intrinsic infectivity of the phages with increasing the mobility of the polycationic chains (or decreasing the hydrogel stiffness), as evidenced in our previous report for $\varphi \mathrm{X} 174$ phages. ${ }^{31}$ Briefly, the underlying mechanism involves the formation of virus-polycations hetero-assemblies, resulting in the screening of the phage capsid receptors operational in cell recognition/infection processes. Figure 7a highlights that (PDADMAC-PAA) and (PLL-HA) are the hydrogels leading to the most pronounced inhibition of T4 infectivity potential, which is line with our previous results (see Figure $3 \mathrm{~b}$ in our previous work ${ }^{31}$ ). Putting aside the cases of (PAH-PGA) and of (PAH-HA) with lowest stiffness (these hydrogels, apparently, do not significantly inhibit the larger infectivity of $\varphi$ X174 as compared to that of T4), similar conclusions may be formulated for $\varphi$ X174-loaded hydrogels (Figure 7b). Here, the maximum is shifted to larger Young modulus probably due to the larger infectivity potential of $\varphi \mathrm{X} 174$ connected to its faster replication cycle. Finally, the percentage of damaged bacteria measured for all hydrogels loaded with T4 and $\varphi$ X174 (Figures S12a,b) follows the trends discussed for (PAH-HA) (Figure S11) as a function of hydrogel stiffness. The additional result is that, unlike for $\varphi$ X174-loaded hydrogel, this percentage of adhered, damaged bacteria exhibits a maximum with increasing the stiffness of T4-loaded hydrogels. This finding relates again to the lower intrinsic infectivity of T4 and, thereby, to its poorer capability to withstand the infectivity inhibition caused by the polycationic chains in the low to moderate hydrogel stiffness regime.

It is stressed that data in Figure 7 reflect specifically the antibacterial activity of the loaded phages, i.e. they are corrected for the bacteriolytic activity of the only polycationic chains (see discussion above) of the hydrogels devoid of phages, with having in mind that polycationic 
chains may affect loaded-phages infectiosity depending on their mobility in the hydrogel, as previously argued. Figure 7 contains antibacterial-related data of phages loaded in 5 different types of hydrogels constructed with different combinations of polycationic and polyanionic building blocks, all exhibiting different charges, different hydrophilic/hydrophobic balances (see molecular structures in Table 1). Despite this spectrum of physicochemical properties, $100 \%$ and $80 \%$ of the data collected for T4 and $\varphi$ X174, respectively (Figure 7), strikingly falls within a bell-shaped master curve as a function of hydrogel stiffness, which demonstrates that hydrogel stiffness is critical in defining the antibacterial performance of phages-loaded hydrogels.

\section{Conclusions}

In this work, we demonstrate that $\varphi \mathrm{X} 174$ and T4 bacteriophages can be entrapped by passive diffusion within the polyelectrolyte multilayer-based hydrogels whose cationic and anionic building units are listed in Table 1. We further show that there is no significant impact of the stiffness of these hydrogels on the kinetics of $\varphi$ X174 and T4 loading nor on the maximal viral storage capacity the hydrogel can sustain. In addition, we evidence that the bacterial adhesion of E. coli B and C can be efficiently triggered by hydrogel stiffness and that antimicrobial activity of hydrogels lacking phages is the result of the bacteriolytic action of sufficiently mobile polycationic chains. We further quantify the respective antimicrobial activities of T4and $\varphi$ X174-loaded hydrogels as a function of hydrogel stiffness. We show that the antimicrobial performance of these phages-loaded hydrogels is the result of a subtle interplay between the defining replication properties of the phages allowing or not the occurrence of an 'infection snowball effect', the inherent bacteriolytic action of sufficiently mobile polycationic chains, and the inhibition of phages infectivity following the (electrostatic) interaction of phages capsid with its polycationic chains environment. The choice of lytic 
viruses to be hosted within the hydrogel matrices should be obviously adapted to kill targeted bacteria other than those considered in this work and to promote a replication of the viruses as fast as possible. Viruses with short replication cycle could help to minimize the contact time between bacteria and hydrogels, thereby promoting an earlier lytic snowball effect and a more efficient activity over shorter incubation periods. Additionally, the selection of phages able to infect bacteria in stationary phase would considerably reduce the latency time, thus allowing a rapid 'infection snowball effect' at low temperature. The current work sketches the intricate coupling between biotic and abiotic factors involved in the bacteriolytic action of phagesfunctionalized hydrogels, which paves the way for further improvement of original phagoterapeutic strategies against antibiotics-resistant bacteria.

\section{Acknowledgments}

The authors are indebted to the financial support of the French Agence Nationale de la Recherche (ANR) for MAGENTA project under the reference ANR-14-CE17-0005-01. We thank the Spectroscopy and Microscopy Service Facility (SMI) of LCPME (Université de Lorraine-CNRS - http://www.lcpme.cnrs-nancy.fr) where most of the experiments were performed and the Environmental Molecular Biology Service Facility (BME) of LCPME for phages preparation and purification. We also thank Dr. Philippe Lavalle (Inserm U1121 Biomaterials \& Bioengineering lab, Strasbourg) for CLSM measurements. 


\section{Supporting Information.}

Surface roughness and thickness of native and cross-linked (PAH-HA) hydrogels (Figure S1), Height profiles of scratches for (PAH-HA) hydrogels (Figure S2), SEM micrographs of (PAH-HA) hydrogel unloaded with phages and with various stiffness (Figure S3), CLSM imaging of $\varphi$ X174 phages internalized in native (PAH-HA) (Figure S4), SEM micrographs of (PAH-HA) hydrogels loaded with $\varphi$ X174 and with various stiffness (Figure S5), Correspondence between optical density at $600 \mathrm{~nm}$ and amounts of E. coli B and E. coli $C$ (Figure S6), Epifluorescence images of stained E. coli B and E. coli $C$ (BacLight ${ }^{\mathrm{TM}}$ staining) adhered onto native and cross-linked (PAH-HA) hydrogels after 4h incubation (Figure S7), Surface concentrations of $E$. coli $B$ and $E$. coli $C$ for native and cross-linked (PAH-HA) hydrogels before and after loading with T4 and $\varphi$ X174 phages (Figure S8), Optical density in the supernatant above the surface of native and cross-linked (PAH-HA) hydrogels loaded or not with T4 and $\varphi$ X174 phages (Figure S9), Stability of $\varphi$ X174 loaded (PAH-HA) native hydrogel over 24 hours in $150 \mathrm{mM} \mathrm{NaCl}$ solution (Figure S10), Percentage of damaged bacteria (E. coli $B$ and E. coli $C$ ) at the surface of native and cross-linked (PAH-HA) hydrogels loaded with T4 and $\varphi$ X174 phages (Figure S11), Stiffness for a series of hydrogels with distinct chemistries, and corresponding surface concentrations of damaged bacteria for cases where hydrogels are loaded or not with $\mathrm{T} 4$ and $\varphi \mathrm{X} 174$ phages (Figure S12). The Supporting Information is available free of charge on the ACS Publications website. 


\section{References:}

1. Carlet, J., The gut is the epicentre of antibiotic resistance. Antimicrob Resist Infect Control 2012, 1 (1), 39.

2. Kanerva, M., Gut bacteria and antimicrobial resistance - what to worry about. Duodecim; laaketieteellinen aikakauskirja 2012, 128 (17), 1755-61.

3. von Wintersdorff, C. J. H.; Penders, J.; van Niekerk, J. M.; Mills, N. D.; Majumder, S.; van Alphen, L. B.; Savelkoul, P. H. M.; Wolffs, P. F. G., Dissemination of Antimicrobial Resistance in Microbial Ecosystems through Horizontal Gene Transfer. Frontiers in Microbiology 2016, 7.

4. Nikaido, H., Multidrug resistance in bacteria. Annu. Rev. Biochem. 2009, 78, 119-46.

5. van Duin, D.; Paterson, D. L., Multidrug-Resistant Bacteria in the Community: Trends and Lessons Learned. Infect Dis Clin North Am 2016, 30 (2), 377-390.

6. Basak, S.; Singh, P.; Rajurkar, M., Multidrug Resistant and Extensively Drug Resistant Bacteria: A Study. J Pathog 2016, 2016, 4065603.

7. Ripolin, A.; Quinn, J.; Larraneta, E.; Vicente-Perez, E. M.; Barry, J.; Donnelly, R. F., Successful application of large microneedle patches by human volunteers. Int. J. Pharm. 2017, 521 (1-2), 92-101.

8. Parhi, R.; Suresh, P.; Mondal, S.; Kumar, P. M., Novel penetration enhancers for skin applications: a review. Curr Drug Deliv 2012, 9 (2), 219-30.

9. Frimpong, C.; Straube, W., Multiple Drug Resistance in Normal Skin Flora. Journal of Research in Progress 2019, 2, 64-71.

10. Muhlhofer, H. M. L.; Deiss, L.; Mayer-Kuckuk, P.; Pohlig, F.; Harrasser, N.; Lenze, U.; Gollwitzer, H.; Suren, C.; Prodinger, P.; R, V. O. N. E.-R.; Schauwecker, J., Increased Resistance of Skin Flora to Antimicrobial Prophylaxis in Patients Undergoing Hip Revision Arthroplasty. In Vivo 2017, 31 (4), 673-676.

11. Li, S.; Dong, S.; Xu, W.; Tu, S.; Yan, L.; Zhao, C.; Ding, J.; Chen, X., Antibacterial Hydrogels. Adv Sci (Weinh) 2018, 5 (5), 1700527.

12. Hoque, J.; Bhattacharjee, B.; Prakash, R. G.; Paramanandham, K.; Haldar, J., Dual Function Injectable Hydrogel for Controlled Release of Antibiotic and Local Antibacterial Therapy. Biomacromolecules 2018, 19 (2), 267-278.

13. Veiga, A. S.; Schneider, J. P., Antimicrobial hydrogels for the treatment of infection. Biopolymers 2013, 100 (6), 637-44.

14. Ng, V. W.; Chan, J. M.; Sardon, H.; Ono, R. J.; Garcia, J. M.; Yang, Y. Y.; Hedrick, J. L., Antimicrobial hydrogels: a new weapon in the arsenal against multidrugresistant infections. Adv. Drug Deliv. Rev. 2014, 78, 46-62. 
15. Yang, K.; Han, Q.; Chen, B.; Zheng, Y.; Zhang, K.; Li, Q.; Wang, J., Antimicrobial hydrogels: promising materials for medical application. Int J Nanomedicine 2018, 13, 22172263.

16. Kamoun, E. A.; Kenawy, E. S.; Chen, X., A review on polymeric hydrogel membranes for wound dressing applications: PVA-based hydrogel dressings. $J$ Adv Res 2017, 8 (3), 217-233.

17. Caló, E.; Khutoryanskiy, V. V., Biomedical applications of hydrogels: A review of patents and commercial products. Eur. Polym. J. 2015, 65, 252-267.

18. Ahmed, E. M., Hydrogel: Preparation, characterization, and applications: A review. $J$ Adv Res 2015, 6 (2), 105-21.

19. Croisfelt, F. M.; Tundisi, L. L.; Ataide, J. A.; Silveira, E.; Tambourgi, E. B.; Jozala, A. F.; Souto, E. M. B.; Mazzola, P. G., Modified-release topical hydrogels: a ten-year review. J. Mater. Sci. 2019, 54 (16), 10963-10983.

20. Chen, S.-H.; Li, Z.; Liu, Z.-L.; Cheng, L.; Tong, X.-L.; Dai, F.-Y., Antimicrobial hydrogels with controllable mechanical properties for biomedical application. J. Mater. Res. 2019, 34 (11), 1911-1921.

21. Salmond, G. P.; Fineran, P. C., A century of the phage: past, present and future. Nat. Rev. Microbiol. 2015, 13 (12), 777-86.

22. Hayes, S.; Mahony, J.; Nauta, A.; van Sinderen, D., Metagenomic Approaches to Assess Bacteriophages in Various Environmental Niches. Viruses 2017, 9 (6), 127.

23. Campbell, A., The future of bacteriophage biology. Nat. Rev. Genet. 2003, 4 (6), 4717.

24. Vaks, L.; Benhar, I., Antibacterial application of engineered bacteriophage nanomedicines: antibody-targeted, chloramphenicol prodrug loaded bacteriophages for inhibiting the growth of Staphylococcus aureus bacteria. Methods Mol Biol 2011, 726, 187206.

25. Haq, I. U.; Chaudhry, W. N.; Akhtar, M. N.; Andleeb, S.; Qadri, I., Bacteriophages and their implications on future biotechnology: a review. Virol J 2012, 9, 9.

26. Sunderland, K. S.; Yang, M.; Mao, C., Phage-Enabled Nanomedicine: From Probes to Therapeutics in Precision Medicine. Angew Chem Int Ed Engl 2017, 56 (8), 1964-1992.

27. O'Sullivan, L.; Buttimer, C.; McAuliffe, O.; Bolton, D.; Coffey, A., Bacteriophagebased tools: recent advances and novel applications. F1000Res 2016, 5, 2782.

28. Petrenko, V. A.; Gillespie, J. W., Paradigm shift in bacteriophage-mediated delivery of anticancer drugs: from targeted 'magic bullets' to self-navigated 'magic missiles'. Expert Opin Drug Deliv 2017, 14 (3), 373-384.

29. Summers, W. C., The strange history of phage therapy. Bacteriophage 2012, 2 (2), 130-133. 
30. Abedon, S. T.; García, P.; Mullany, P.; Aminov, R., Phage Therapy: Past, Present and Future. Frontiers in Microbiology 2017, 8 (981).

31. Bacharouche, J.; Erdemli, O.; Rivet, R.; Doucoure, B.; Caillet, C.; Mutschler, A.; Lavalle, P.; Duval, J. F. L.; Gantzer, C.; Francius, G., On the Infectivity of Bacteriophages in Polyelectrolyte Multilayer Films: Inhibition or Preservation of Their Bacteriolytic Activity? ACS Appl. Mater. Interfaces 2018, 10 (39), 33545-33555.

32. Wroe, J. A.; Johnson, C. T.; Garcia, A. J., Bacteriophage delivering hydrogels reduce biofilm formation in vitro and infection in vivo. J Biomed Mater Res A 2020, 108 (1), 39-49.

33. Peivandi, A.; Tian, L.; Mahabir, R.; Hosseinidoust, Z., Hierarchically Structured, Self-Healing, Fluorescent, Bioactive Hydrogels with Self-Organizing Bundles of Phage Nanofilaments. Chem. Mater. 2019, 31 (15), 5442-5449.

34. Henry, M.; Debarbieux, L., Tools from viruses: bacteriophage successes and beyond. Virology 2012, 434 (2), 151-61.

35. Stanford, K.; McAllister, T. A.; Niu, Y. D.; Stephens, T. P.; Mazzocco, A.; Waddell, T. E.; Johnson, R. P., Oral Delivery Systems for Encapsulated Bacteriophages Targeted at Escherichia coli O157:H7 in Feedlot Cattle. J. Food Prot. 2010, 73 (7), 13041312.

36. Hussain, M. A.; Liu, H.; Wang, Q.; Zhong, F.; Guo, Q.; Balamurugan, S., Use of encapsulated bacteriophages to enhance farm to fork food safety. Crit Rev Food Sci Nutr 2017, 57 (13), 2801-2810.

37. Korehei, R.; Kadla, J. F., Encapsulation of T4 bacteriophage in electrospun poly(ethylene oxide)/cellulose diacetate fibers. Carbohydr. Polym. 2014, 100, 150-7.

38. Ma, Y.; Pacan, J. C.; Wang, Q.; Xu, Y.; Huang, X.; Korenevsky, A.; Sabour, P. M., Microencapsulation of bacteriophage felix $\mathrm{O} 1$ into chitosan-alginate microspheres for oral delivery. Appl. Environ. Microbiol. 2008, 74 (15), 4799-805.

39. Matinkhoo, S.; Lynch, K. H.; Dennis, J. J.; Finlay, W. H.; Vehring, R., Spray-dried respirable powders containing bacteriophages for the treatment of pulmonary infections. $J$. Pharm. Sci. 2011, 100 (12), 5197-205.

40. Choińska-Pulit, A.; Mituła, P.; Śliwka, P.; Łaba, W.; Skaradzińska, A., Bacteriophage encapsulation: Trends and potential applications. Trends Food Sci. Technol. 2015, 45 (2), 212-221.

41. Decher, G.; Hong, J. D.; Schmitt, J., Buildup of ultrathin multilayer films by a selfassembly process. Consecutively alternating adsorption of anionic and cationic polyeletrolytes on charges surface. Thin Solid Films 1992, 210, 831-835.

42. Ariga, K.; Hill, J. P.; Ji, Q., Layer-by-layer assembly as a versatile bottom-up nanofabrication technique for exploratory research and realistic application. Phys. Chem. Chem. Phys. 2007, 9 (19), 2319-40. 
43. Francius, G.; Hemmerle, J.; Ohayon, J.; Schaaf, P.; Voegel, J. C.; Picart, C.; Senger, B., Effect of crosslinking on the elasticity of polyelectrolyte multilayer films measured by colloidal probe AFM. Microsc Res Tech 2006, 69 (2), 84-92.

44. Tengvall, P.; Jansson, E.; Askendal, A.; Thomsen, P.; Gretzer, C., Preparation of multilayer plasma protein films on silicon by EDC/NHS coupling chemistry. Colloids Surf., $B$ 2003, 28 (4), 261-272.

45. Conceição-Neto, N.; Zeller, M.; Lefrère, H.; De Bruyn, P.; Beller, L.; Deboutte, W.; Yinda, C. K.; Lavigne, R.; Maes, P.; Van Ranst, M.; Heylen, E.; Matthijnssens, J., Modular approach to customise sample preparation procedures for viral metagenomics: a reproducible protocol for virome analysis. Sci Rep 2015, 5, 16532-16532.

46. Quiles, F.; Saadi, S.; Francius, G.; Bacharouche, J.; Humbert, F., In situ and real time investigation of the evolution of a Pseudomonas fluorescens nascent biofilm in the presence of an antimicrobial peptide. Biochim. Biophys. Acta, Biomembr. 2016, 1858 (1), 7584.

47. Zaet, A.; Dartevelle, P.; Daouad, F.; Ehlinger, C.; Quiles, F.; Francius, G.; Boehler, C.; Bergthold, C.; Frisch, B.; Prevost, G.; Lavalle, P.; Schneider, F.; Haikel, Y.; Metz-Boutigue, M. H.; Marban, C., D-Cateslytin, a new antimicrobial peptide with therapeutic potential. Sci. Rep. 2017, 7 (1), 15199.

48. Mosier-Boss, P. A.; Lieberman, S. H.; Andrews, J. M.; Rohwer, F. L.; Wegley, L. E.; Breitbart, M., Use of fluorescently labeled phage in the detection and identification of bacterial species. Appl. Spectrosc. 2003, 57 (9), 1138-44.

49. Pinheiro, M. D.; Power, M. E.; Butler, B. J.; Dayeh, V. R.; Slawson, R.; Lee, L. E.; Lynn, D. H.; Bols, N. C., Use of Tetrahymena thermophila to study the role of protozoa in inactivation of viruses in water. Appl. Environ. Microbiol. 2007, 73 (2), 643-9.

50. Sneddon, I. N., The relation between load and penetration in the axisymmetric Boussinesq problem for a punch of arbitrary profile. Int. J. Eng. Sci. 1965, 3 (1), 47-57.

51. Gavara, N.; Chadwick, R. S., Determination of the elastic moduli of thin samples and adherent cells using conical atomic force microscope tips. Nat. Nanotechnol. 2012, 7 (11), 733-6.

52. Polyakov, P.; Soussen, C.; Duan, J.; Duval, J. F. L.; Brie, D.; Francius, G., Automated force volume image processing for biological samples. PLoS One 2011, 6 (4), e18887.

53. Schneider, A.; Francius, G.; Obeid, R.; Schwinte, P.; Hemmerle, J.; Frisch, B.; Schaaf, P.; Voegel, J. C.; Senger, B.; Picart, C., Polyelectrolyte multilayers with a tunable Young's modulus: influence of film stiffness on cell adhesion. Langmuir 2006, 22 (3), 1193200.

54. Goycoolea, F. M.; Heras, A.; Aranaz, I.; Galed, G.; Fernández-Valle, M. E.; Argüelles-Monal, W., Effect of Chemical Crosslinking on the Swelling and Shrinking Properties of Thermal and pH-Responsive Chitosan Hydrogels. Macromol. Biosci. 2003, 3 (10), 612-619. 
55. Mermut, O.; Lefebvre, J.; Gray, D. G.; Barrett, C. J., Structural and mechanical properties of polyelectrolyte multilayer films studied by AFM. Macromolecules 2003, 36 (23), 8819-8824.

56. Vyborny, K.; Vallova, J.; Koci, Z.; Kekulova, K.; Jirakova, K.; Jendelova, P.; Hodan, J.; Kubinova, S., Genipin and EDC crosslinking of extracellular matrix hydrogel derived from human umbilical cord for neural tissue repair. Sci Rep 2019, 9 (1), 10674.

57. Hua, J.; Li, Z.; Xia, W.; Yang, N.; Gong, J.; Zhang, J.; Qiao, C., Preparation and properties of EDC/NHS mediated crosslinking poly (gamma-glutamic acid)/epsilonpolylysine hydrogels. Materials science \& engineering. C, Materials for biological applications 2016, 61, 879-92.

58. Roy, B.; Philippe, C.; Loessner, M. J.; Goulet, J.; Moineau, S., Production of Bacteriophages by Listeria Cells Entrapped in Organic Polymers. Viruses 2018, 10 (6).

59. Fattouh, F. A.; Aassar, S. A. E. L.; Farag, A. E. M.; Hassan, S. W., Effect of Coliphage Entrapment on its Interaction with the Host Bacterium. Biotechnology(Faisalabad) 2003, 2 (2), 94-100.

60. Song, F.; Ren, D., Stiffness of cross-linked poly(dimethylsiloxane) affects bacterial adhesion and antibiotic susceptibility of attached cells. Langmuir 2014, 30 (34), 10354-62.

61. Guegan, C.; Garderes, J.; Le Pennec, G.; Gaillard, F.; Fay, F.; Linossier, I.; Herry, J. M.; Fontaine, M. N.; Rehel, K. V., Alteration of bacterial adhesion induced by the substrate stiffness. Colloids Surf., B 2014, 114, 193-200.

62. Straub, H.; Bigger, C. M.; Valentin, J.; Abt, D.; Qin, X. H.; Eberl, L.; ManiuraWeber, K.; Ren, Q., Bacterial Adhesion on Soft Materials: Passive Physicochemical Interactions or Active Bacterial Mechanosensing? Adv Healthc Mater 2019, 8 (8), e1801323.

63. Kolewe, K. W.; Zhu, J.; Mako, N. R.; Nonnenmann, S. S.; Schiffman, J. D., Bacterial Adhesion Is Affected by the Thickness and Stiffness of Poly(ethylene glycol) Hydrogels. ACS Appl. Mater. Interfaces 2018, 10 (3), 2275-2281.

64. Lichter, J. A.; Thompson, M. T.; Delgadillo, M.; Nishikawa, T.; Rubner, M. F.; Van Vliet, K. J., Substrata mechanical stiffness can regulate adhesion of viable bacteria. Biomacromolecules 2008, 9 (6), 1571-8.

65. Gordon, V. D.; Wang, L., Bacterial mechanosensing: the force will be with you, always. J. Cell Sci. 2019, 132 (7), jcs227694.

66. Jourdainne, L.; Lecuyer, S.; Arntz, Y.; Picart, C.; Schaaf, P.; Senger, B.; Voegel, J. C.; Lavalle, P.; Charitat, T., Dynamics of poly(L-lysine) in hyaluronic acid/poly(L-lysine) multilayer films studied by fluorescence recovery after pattern photobleaching. Langmuir 2008, 24 (15), 7842-7.

67. Nazaran, P.; Bosio, V.; Jaeger, W.; Anghel, D. F.; Klitzing, R. V., Lateral mobility of polyelectrolyte chains in multilayers. J. Phys. Chem. B 2007, 111 (29), 8572-81. 
68. Xu, L.; Kozlovskaya, V.; Kharlampieva, E.; Ankner, J. F.; Sukhishvili, S. A., Anisotropic Diffusion of Polyelectrolyte Chains within Multilayer Films. ACS Macro Lett 2011, 2012 (1), 127-130.

69. Jazwinski, S. M.; Lindberg, A. A.; Kornberg, A., The lipopolysaccharide receptor for bacteriophages $\phi X 174$ and S13. Virology 1975, 66 (1), 268-282.

70. Rakhuba, D. V.; Kolomiets, E. I.; Dey, E. S.; Novik, G. I., Bacteriophage Receptors, Mechanisms of Phage Adsorption and Penetration into Host Cell. Polish Journal of Microbiology 2010, 59 (3), 145-155.

71. De Paepe, M.; Taddei, F., Viruses' life history: towards a mechanistic basis of a tradeoff between survival and reproduction among phages. PLoS Biol. 2006, 4 (7), e193.

72. Dressman, H. K.; Drake, J. W., Lysis and lysis inhibition in bacteriophage T4: rV mutations reside in the holin t gene. J. Bacteriol. 1999, 181 (14), 4391-6.

73. Young, K. D.; Anderson, R. J.; Hafner, R. J., Lysis of Escherichia coli by the bacteriophage $\phi X 174 \mathrm{E}$ protein: inhibition of lysis by heat shock proteins. J. Bacteriol. 1989, $171(8), 4334-41$.

74. Taj, M.; Ling, J.; Bing, L.; Zhang, Q.; Hassani, I.; Hassani, T.; Samreen, Z.; Yunlin, W., Effect of dilution, temperature and $\mathrm{pH}$ on the lysis activity of T4 phage against E.coli BL21. Journal of Animal and Plant Sciences 2014, 24, 2014-1252.

75. Shao, Y.; Wang, I.-N., Bacteriophage adsorption rate and optimal lysis time. Genetics 2008, 180 (1), 471-482.

76. Wang, I.-N., Lysis timing and bacteriophage fitness. Genetics 2006, 172 (1), 17-26.

77. Jaiswal, M.; Xavier, J.; Carrow, J.; Desai, P.; Alge, D.; Gaharwar, A., Mechanically Stiff Nanocomposite Hydrogels at Ultralow Nanoparticle Content. ACS Nano 2015, 10 (1), 246-256.

78. Thoniyot, P.; Tan, M. J.; Karim, A. A.; Young, D. J.; Loh, X. J., NanoparticleHydrogel Composites: Concept, Design, and Applications of These Promising, MultiFunctional Materials. Advanced Science 2015, 2 (1-2), 1400010.

79. Dannert, C.; Stokke, B. T.; Dias, R. S., Nanoparticle-Hydrogel Composites: From Molecular Interactions to Macroscopic Behavior. Polymers 2019, 11 (2), 275.

80. Levin, M.; Sonn-Segev, A.; Roichman, Y., Structural changes in nanoparticlehydrogel composites at very low filler concentrations. J. Chem. Phys. 2019, 150 (6), 064908. 
FIGURE AND TABLE CAPTIONS.

\section{TABLES}

Table 1. List of polyelectrolytes used for hydrogel construction, and details of their physicochemical and cell-growth inhibition properties. $\mathrm{MIC}_{100}$ is defined as the minimal concentration of polyelectrolytes leading to a complete inhibition of bacterial growth.

Scheme 1. Hydrogel build-up and bacteria killing-viruses loading procedure in the design of antimicrobial matrices based on phagotherapy.

Figure 1: AFM height images of (PAH-HA) hydrogel before and after cross-linking with EDC at $1 \mathrm{mg} / \mathrm{mL}, 2 \mathrm{mg} / \mathrm{mL}, 5 \mathrm{mg} / \mathrm{mL}, 10 \mathrm{mg} / \mathrm{mL}$ and $50 \mathrm{mg} / \mathrm{mL}$ (indicated).

Figure 2. Evolution of (PAH-HA) hydrogel stiffness as a function of EDC cross-linker concentration (a), and evolution of the swelling ratio of (PAH-HA) hydrogels as a function of their corresponding stiffness (b). Stiffnesses and swelling ratios were calculated from AFM nanoindentation and imaging experiments respectively.

Figure 3. Evolution of the number of phages entrapped within the hydrogels as a function of time a) for (PAH-HA) cross-linked at $5 \mathrm{mg} / \mathrm{mL}$ in EDC and b) after $24 \mathrm{~h}$ phages-loading as a function of hydrogel stiffness (or elasticity). Blue circles and red squares correspond to counting of T4 and $\varphi$ X174 by plaque counting methods, respectively. Phages were inoculated at concentrations of $2.4 \times 10^{7} \mathrm{PFU} / \mathrm{mL}$ and $2.7 \times 10^{7} \mathrm{PFU} / \mathrm{mL}$ for $\varphi \mathrm{X} 174$ and $\mathrm{T} 4$ phages, respectively. 
Figure 4. Evolution of a) adhered (which includes both intact and damaged cells) and b) damaged E. coli B and E. coli C (indicated) concentrations (in a) or fraction (in b), respectively, as a function of (PAH-HA) hydrogel elasticity tuned via chemical cross-linking procedure and determined by AFM (Figure 2). Measurements were performed after $4 \mathrm{~h}$ exposure of the hydrogels free of phages to the bacterial suspensions. In panel $b$, the percentage of damaged bacteria is evaluated with respect to the total amount of cells adhered onto the hydrogel surface. See details in the text.

Figure 5. Evolution of the concentration of E. coli $\mathrm{B}$ and E. coli $\mathrm{C}$ adhered onto the surface of native and cross-linked (PAH-HA) hydrogels, before and after loading with a) T4 phages and b) $\varphi \mathrm{X} 174$ phages, as a function of hydrogel stiffness.

Figure 6. Antibacterial activity against a) E. coli B (targeted by T4) and b) E. coli C (targeted by $\varphi \mathrm{X} 174)$ either adhered at the surface of native and cross-linked (PAH-HA) hydrogels or in the supernatant covering the hydrogels loaded with T4 (panel a) and $\varphi$ X174 (panel b) phages. Results are displayed as a function of hydrogel stiffness.

Figure 7. Antibacterial activity of hydrogels hosting $\mathrm{T} 4$ and $\varphi \mathrm{X} 174$ phages against a) E. coli B and b) E. coli C, respectively, as a function of hydrogel stiffness. Red circles correspond to data pertaining to the native and cross-linked (PAH-HA) hydrogels, while triangles up, triangles down, squares and diamonds correspond to (PDADMAC-PAA), (PLL-HA), (PAHPGA) and (PAH-PAA) hydrogels, respectively. 